\title{
Growth factors and membrane depolarization activate distinct programs of early response gene expression: dissociation of fos and jun induction
}

\author{
David P. Bartel, ${ }^{1,2}$ Morgan Sheng, ${ }^{1}$ Lester F. Lau, ${ }^{3}$ and Michael E. Greenberg ${ }^{1,4}$ \\ ${ }^{1}$ Department of Microbiology and Molecular Genetics and ${ }^{2}$ Committee on Virology, Harvard Medical School, Boston, \\ Massachusetts 02115 USA; $^{3}$ Department of Molecular Biology, Northwestern University Medical School, Chicago, Illinois \\ 60611 USA
}

\begin{abstract}
A set of early response genes has been identified whose transcription in fibroblasts is rapidly induced in response to growth factors. Prototype members of this group, c-fos and c-jun, encode products that form a heterodimer and have been implicated in the regulation of gene expression and cell growth. It is thought that other early response genes also encode critical mediators of the cell's response to external stimuli. We have used PC12 pheochromocytoma cells as a model system to test the hypothesis that different extracellular signals induce distinct patterns of expression of early response genes. Our results indicate that membrane depolarization, induced either by potassium chloride or by the neurotransmitter analog nicotine, activates a program of gene expression distinct from that activated by nerve growth factor or epidermal growth factor. Notably, c-fos and c-jun activation can be dissociated; whereas c-jun is coinduced with c-fos and jun-B after growth factor stimulation, membrane depolarization activates c-fos and jun-B without stimulating c-jun. Fos may therefore form transcription complexes with alternative cofactors under different stimulation conditions. nur/77 and zif/268, which encode putative transcription factors, also show markedly different responses to growth factors and depolarization. We conclude that multiple nonconvergent signal transduction pathways control early response gene expression. Our findings also indicate that the diversity and specificity of cellular response to environmental change can be accounted for by the differential combinatorial induction of a relatively small number of early response genes.
\end{abstract}

[Key Words: Transcriptional regulation; growth factors; membrane depolarization; c-fos; jun; signal transduction]

Received December 27, 1988; revised version accepted January 27, 1989.

A class of cellular genes, termed early response or immediate early genes, has been identified whose transcription is rapidly and transiently activated when quiescent fibroblasts are stimulated by growth factors to re-enter the cell cycle (Cochran et al. 1983; Greenberg and Ziff 1984; Lau and Nathans 1985, 1987; Lim et al. 1987; Sukhatme et al. 1987; Almendral et al. 1988). Recent experiments indicate that several members of the early response gene family encode putative transcription factors that may be critical mediators of the cell's response to growth factors (Chavrier et al. 1988; Chiu et al. 1988; Christy et al. 1988; Hazel et al. 1988; Joseph et al. 1988; Lemaire et al. 1988). The c-fos and c-jun proto-oncogenes are the most extensively studied of these genes. c-jun, the cellular counterpart of the transforming gene of avian sarcoma virus 17 (Maki et al. 1987), encodes a

${ }^{4}$ Corresponding author.
DNA-binding protein that is the major polypeptide present in purified preparations of the transcription factor AP-1 (Bohmann et al. 1987; Angel et al. 1988b). Jun/AP-1 binds specifically to a phorbol ester-responsive sequence $\left(5^{\prime}\right.$-ATGACTCAT- $\left.{ }^{\prime}\right)$, first identified in the SV40 and human metallothionein IIA enhancers (Angel et al. 1987; Lee et al. 1987). Recent evidence indicates that the c-jun protein forms a complex with the product of the c-fos proto-oncogene (Rauscher et al. 1988b; Sassone-Corsi et al. 1988a; for review, see Curran and Franza 1988). As a heterodimer, c-fos and c-jun proteins bind to the AP-1 site with high affinity and regulate transcription of genes containing this DNA element (Halazonetis et al. 1988; Kouzarides and Ziff 1988; Nakabeppu et al. 1988, Rauscher et al. 1988a; SassoneCorsi et al. 1988b).

Two other early response genes, $j u n-B$ and jun-D, have sequence similarity to $\mathrm{c}$-jun and may form transcription complexes with c-fos (Nakabeppu et al. 1988; Ryder et 
al. 1988). Additional members of the early response gene family appear to encode transcription factors of other classes. These include zif/268 and Krox-20, two closely related genes with zinc-finger DNA-binding domains (Chavrier et al. 1988; Christy et al. 1988; Sukhatme et al. 1987, 1988), and nur/77, an early response gene with sequence similarity to the glucocorticoid receptor (Hazel et al. 1988; Milbrandt 1988).

c-fos has become a model gene for the study of inducible expression. Transcription of c-fos is barely detectable prior to growth factor addition, but within minutes after treatment its transcription is elevated $>100$-fold (Cochran et al. 1984; Greenberg and Ziff 1984; Kruijer et al. 1984; Muller et al. 1984). c-fos activation occurs in a wide range of cell types in response to a diverse set of agents including specific polypeptide growth factors, serum, phorbol esters, neurotransmitters, and agents that elevate intracellular calcium and cAMP /Greenberg et al. 1985, 1986). The regulation of c-jun and other early response genes by extracellular stimuli is less well characterized. An important question is whether the jun family and the other early response genes are always coinduced with c-fos, as they are in fibroblasts stimulated with serum (Lamph et al. 1988; Quantin and Breathnach 1988; Ryder and Nathans 1988; Ryseck et al. 1988), or whether these genes are regulated differentially under some conditions. An attractive hypothesis is that the different effects of various extracellular stimuli on cell physiology are mediated by the activation of distinct subsets of early response genes.

The rat pheochromocytoma PC12 cell line is well suited for testing this hypothesis because it can be stimulated by an array of agents that have disparate effects on the cells' phenotype (Greene and Tischler 1976; for review, see Greene and Tischler 1982). For instance, nerve growth factor (NGF) has an initial mitogenic effect on PC12 cells but then causes growth arrest and differentiation into sympathetic neuron-like cells (Greene and Tischler 1976, 1982; Boonstra et al. 1983). Epidermal growth factor (EGF) is also mitogenic for PC12 cells, but in contrast to NGF it does not induce growth arrest or neuronal differentiation (Boonstra et al. 1983). $\mathrm{PC} 12$ cells also provide a good system for studying the effects of electrical signals on neuronal gene expression because they have excitable membranes that can be depolarized by specific neurotransmitters or elevated levels of $\mathrm{KCl}$ (for review, see Greene and Tischler 1982).

We describe experiments demonstrating that stimulation of $\mathrm{PC} 12$ cells with membrane depolarizing agents induces a program of early response gene transcription that is distinct from the pattern observed upon treatment with growth factors. Although c-fos, c-jun, and jun-B transcription are all activated by growth factors, membrane depolarization stimulates $\mathrm{c}-f \circ s$ and jun-B but fails to activate c-jun. A differential response of other early response genes is also observed. These results lead to two important conclusions. First, multiple nonconvergent pathways must exist to transduce cell-surface signals to promoters of early response genes in the nucleus. Second, the different effects of growth factors and neurotransmitters on cell physiology may be mediated by the action of distinct combinations of early response genes, including c-fos and members of the jun family.

\section{Results}

Regulation of $c$-jun, jun- $B$, and $c$-fos $m R N A$ in PC12 cells

PC12 cells can be stimulated by a wide array of agents including NGF, EGF, cAMP analogs, and neurotransmitters (Greene and Tischler 1982). Although these various stimuli elicit distinct cellular responses in $\mathrm{PCl} 2$ cells, all of the agents activate c-fos transcription (Curran and Morgan 1985; Greenberg et al. 1985, 1986; Kruijer et al. 1985; Morgan and Curran 1986). The recent finding that the $\mathrm{c}$-fos gene product forms a complex with $\mathrm{c}-j u n$ and jun-B proteins raises the possibility that the action of c-fos might be modulated by the relative abundance of $\mathrm{c}-j u n$, jun-B, or other jun-related genes. Therefore, we asked whether c-jun and jun-B are activated in concert with c-fos when $\mathrm{PCl} 2$ cells are stimulated with these different agents.

Using Northern blot analysis, we find that both NGF and EGF cause a marked increase in c-jun and jun-B mRNAs within 30 min after their addition to PC12 cells (Fig. 1). The induction is similar to that seen for c-fos, but the relative increase is not as dramatic, perhaps due to higher constitutive expression of the jun genes. In addition, induction of jun-B mRNA appears to follow slightly slower kinetics than that of c-fos or c-jun mRNA. Of interest is the observation that two jun-B mRNA species are detected that differ in size by $\sim 200$ bp (Fig. 1). The 2.1-kb jun-B mRNA is induced within 15 min and decays rapidly. The smaller iun-B mRNA accumulates with slower kinetics. The $1.9-\mathrm{kb}$ species could be a degradation intermediate of the longer transcript, but the data do not exclude the possibility that it is a product of alternative transcriptional initiation, splicing, or poly(A) addition. The 2.7- and 3.4-kb c-jun mRNAs detected in $\mathrm{PCl} 2$ cells upon induction with growth factors (Fig. 1) most likely differ at their 3 ' ends, as has been shown recently for the c-jun mRNAs in fibroblasts (Ryseck et al. 1988).

No significant differences are evident when NGF induction of c-jun and jun-B is compared with EGF stimulation of these genes (Fig. 1). This suggests that the different effects of NGF and EGF on PC12 cell physiology are not a consequence of differential induction of the constituents of Fos/Jun complexes.

Exposure of PC12 cells to elevated extracellular levels of $\mathrm{KCl}$ results in membrane depolarization, followed by an influx of extracellular calcium. Depolarization of PC12 cells causes the rapid induction of c-fos transcription via a signal transduction pathway that is distinct from the pathway by which growth factors activate $\mathrm{c}$-fos (Sheng et al. 1988). In contrast to c-fos, which is induced at least 50 -fold by membrane depolarization, we find less than a 3-fold change in the level of c-jun mRNA upon treatment with elevated $\mathrm{KCl}$ (Fig. 1). This slight 


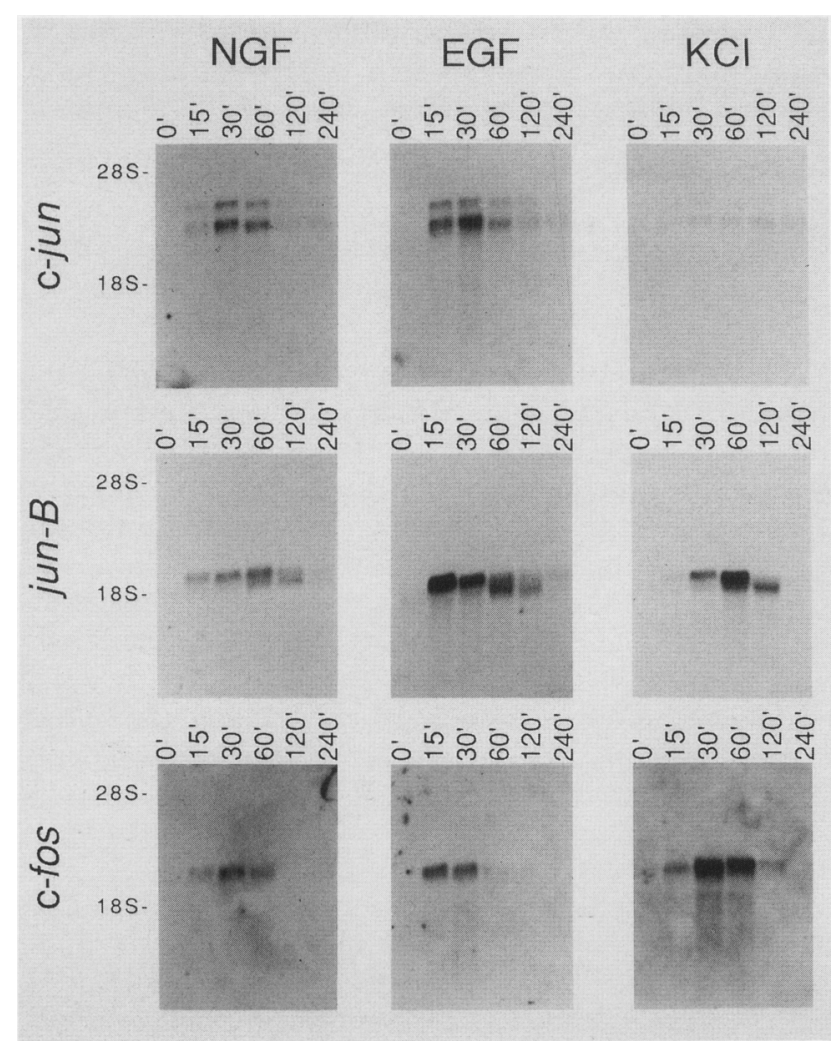

Figure 1. Induction of c-jun, jun-B, and c-fos mRNA in PC12 cells stimulated by growth factors or membrane depolarization. Samples of cytoplasmic RNA (15 $\mu \mathrm{g})$ from cells at specified times $(0-240 \mathrm{~min})$, after stimulation with $50 \mathrm{ng} / \mathrm{ml} \mathrm{NGF,} 3$ $\mathrm{ng} / \mathrm{ml} \mathrm{EGF}$, or $60 \mathrm{mM} \mathrm{KCl}$, were assayed by Northern blot analysis as described in Materials and methods. The same filters were stripped successively and hybridized with oligoprimed ${ }^{32} \mathrm{P}-$ labeled cDNA probes specific for c-jun, jun-B, and c-fos. Positions of $28 \mathrm{~S}$ and $18 \mathrm{~S}$ ribosomal mRNAs are indicated.

increase is slow and persistent, unlike the typical mRNA response of early response genes. Like c-fos, jun-B mRNA accumulates rapidly and dramatically when the PC12 cell membrane is depolarized (Fig. 1). EGTA abrogates c-fos and jun-B activation (data not shown), consistent with induction depending on influx of extracellular $\mathrm{Ca}^{2+}$. These results, summarized in Table 1, indicate that membrane depolarization induces

Table 1. Fold induction of fos and jun mRNA levels in PC12 cells by specific stimuli

\begin{tabular}{lccc}
\hline Gene & NGF & EGF & KCl \\
\hline c-jun & 8 & 18 & $<3$ \\
jun-B & 8 & 10 & 23 \\
c-fos & 31 & 43 & 56 \\
\hline
\end{tabular}

The levels of c-jun, jun-B, and c-fos mRNAs before and after stimulation with the indicated agents were quantitated by scanning laser densitometry of the autoradiographs in Fig. 1. The values represent the ratio of the peak poststimulation mRNA level to the basal prestimulation mRNA level. Densitometry of blots stripped and rehybridized with a raf probe served to normalize for RNA content between lanes. a program of gene expression that is distinct from that seen with growth factors and may not involve c-jun.

The observation that membrane depolarization stimulates jun-B expression but activates c-jun only minimally prompted us to examine the induction of these genes in NGF-differentiated PC12 cells by the nicotinic cholinergic receptor agonist nicotine. Upon exposure to NGF for several days, PC12 cells acquire many properties of sympathetic neurons, including the expression of increased levels of the nicotinic cholinergic receptor (Jumblatt and Tischler 1982; Amy and Bennett 1983). Treatment of NGF-differentiated PC12 cells with nicotinic receptor agonists causes membrane depolarization, generating a sodium action potential and the release of neurotransmitter at the axon terminus (Dichter et al. 1977). We have shown previously that stimulation of NGF-differentiated PC12 cells with nicotine results in the rapid activation of c-fos transcription /Greenberg et al. 1986; see also Fig. 2). The induction signal is transduced through the nicotinic cholinergic receptor and is dependent on an influx of calcium ions through voltagegated calcium channels. As shown in Figure 2, nicotine stimulates jun-B mRNA levels in parallel with c-fos but has no effect on c-jun expression. The activation of both c-fos and jun-B is dependent on the influx of extracellular calcium inasmuch as the induction of these two mRNAs is completely blocked by the presence of EGTA in the medium (Fig. 2). Similar results are obtained following membrane depolarization of NGF-differentiated cells by $\mathrm{KCl}$ addition (data not shown). The relative increase in jun-B mRNA in NGF-differentiated PC12 cells

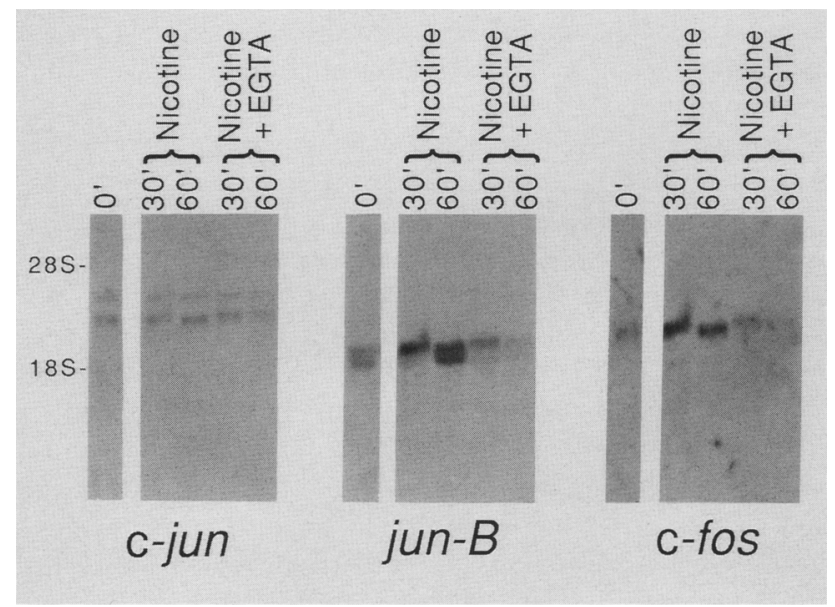

Figure 2. Analysis of jun and fos mRNA in NGF-differentiated $\mathrm{PCl} 2$ cells following voltage-gated $\mathrm{Ca}^{2+}$ influx. $\mathrm{PC1} 2$ cells allowed to differentiate for 3 days in the presence of $50 \mathrm{ng} / \mathrm{ml}$ NGF were depolarized with $0.10 \mathrm{~mm}$ nicotine or $0.10 \mathrm{~mm}$ nicotine plus $3.0 \mathrm{~mm}$ EGTA. Northern analysis of cytoplasmic RNA from cells 0,30 , and $60 \mathrm{~min}$ after stimulation was carried out as described in Fig. 1. Positions of $28 \mathrm{~S}$ and $18 \mathrm{~S}$ ribosomal mRNAs are indicated. 
is lower than that in undifferentiated cells and may be a consequence of the higher basal level of jun-B mRNA that is present after NGF-induced differentiation (data not shown). The findings with nicotine extend the results obtained with $\mathrm{KCl}$. They indicate that membrane depolarization by either a neurotransmitter receptor agonist or $\mathrm{KCl}$ induces a program of gene expression that differs from that seen with growth factors. Furthermore, the experiments demonstrate that induction of $c$-fos and c-jun can be dissociated.

Using a nuclear run-on transcription assay, we establish that the differential response of c-jun and c-fos mRNA to membrane depolarization reflects a difference in the transcription of these two genes. In these experiments membrane depolarization induces $\mathrm{c}$-fos and jun-B transcription significantly within $15 \mathrm{~min}$, but has no detectable effect on the level of c-jun transcription (Fig. $3 \mathrm{~A}$ ). Previously, we have shown that membrane depolarization fails to activate transcription of $\beta$-actin, another growth-factor-inducible gene (Greenberg et al. 1986; see also Fig. 3A). The effects of NGF and EGF on c-iun and jun-B transcription correlate with the transient increase in mRNA of these two genes (Figs. 1 and 3A).

The low c-iun signals observed in the run-on transcription assay shown in Figure $3 \mathrm{~A}$ contrasts with the strong c-jun signals observed by others when quiescent fibroblasts are stimulated to re-enter the cell cycle by the addition of calf serum (Quantin and Breathnach 1988; Ryder and Nathans 1988; Ryseck et al. 1988). To rule out the possibility that the lower c-jun run-on transcription signal in PC12 cells is due to poor hybridization of rat c-jun transcripts to the human c-jun plasmid DNA used in the run-on assay, an experiment was carried out with quiescent rat $208 \mathrm{~F}$ fibroblast cells stimulated by serum addition. In contrast to the results obtained in $\mathrm{PCl} 2$ cells, the c-jun and jun-B transcription signals are comparable in rat fibroblasts after serum stimulation (Fig. 4), confirming the validity of our run-

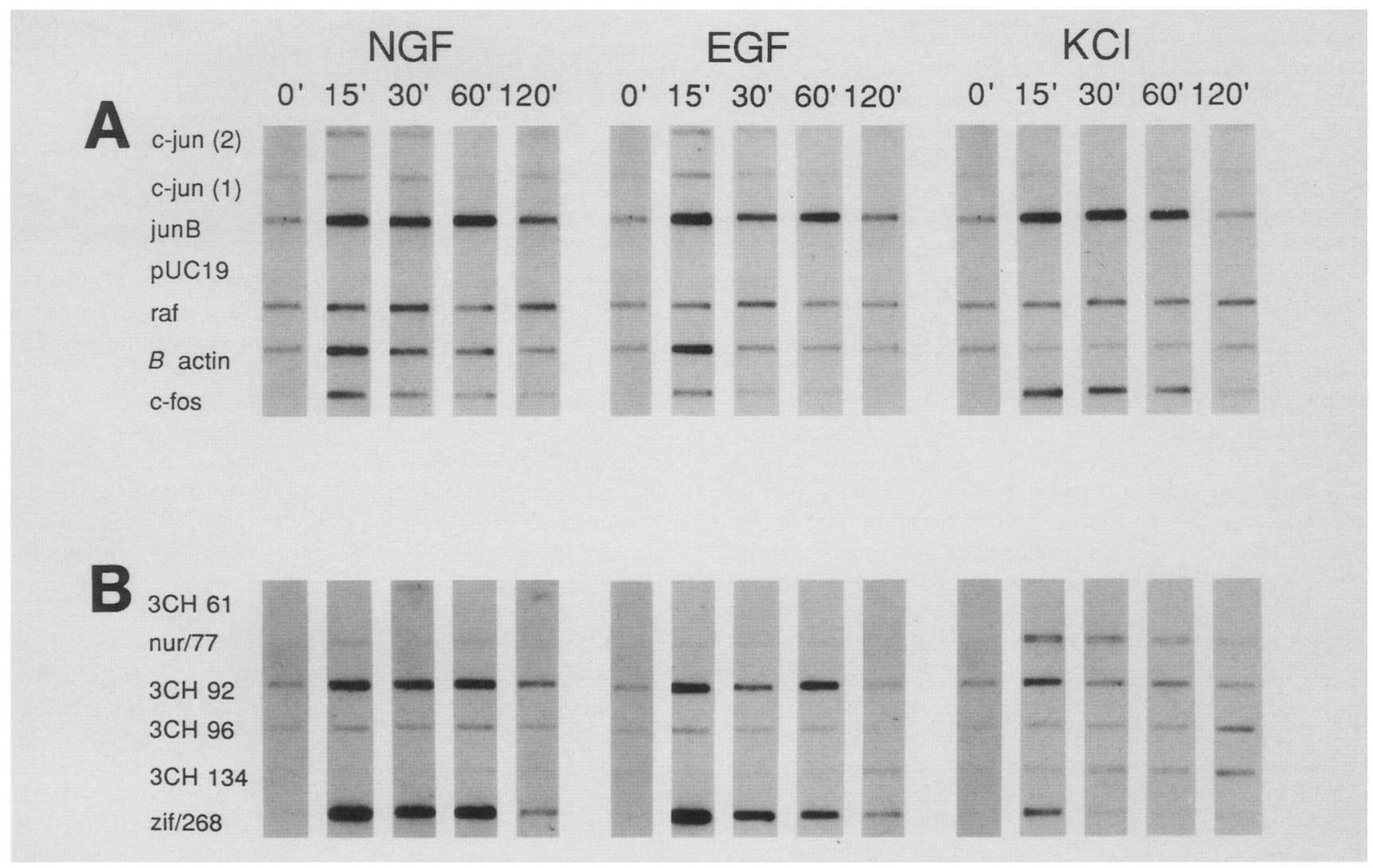

Figure 3. Nuclear run-on transcription analysis of early response genes in PCl2 cells stimulated with growth factors or $\mathrm{KCl}$ membrane depolarization. Plasmids containing early response gene cDNAs were spotted onto nitrocellulose filters and hybridized with ${ }^{32}$ P-labeled run-on transcripts from nuclei obtained from the same cells harvested for Northern analysis in Fig. 1 . pUC19 and raf serve as a negative and a constant internal control, respectively (Greenberg and Ziff 1984). (A) Hybridization of run-on transcripts to iun, fos, $\beta$-actin, and control plasmids; $(B)$ run-on transcript hybridization to the other early response gene cDNAs. Each filter in $B$ was hybridized and washed, together with the corresponding filter in $A$. 
on transcription analysis using these plasmids. Indeed, c-jun transcription appears significantly greater in serum-stimulated fibroblasts than in PC12 cells activated by growth factors (Fig. 3A) or by serum (data not shown). This apparent cell type difference is evident both before and after stimulation. It results in at least a fivefold difference between the two cell types in the ratio of c-jun to jun-B transcription signals (Figs. 3A and 4).

\section{Activation of additional early response genes in PC12 cells}

The experiments described above indicate that members of the jun family respond differently to growth factors and membrane depolarizing agents. We next asked whether other early response genes are also differentially regulated by these stimuli. NGF, EGF, and elevated levels of $\mathrm{KCl}$ were tested for their ability to activate the transcription of six additional early response genes. These early response genes were shown previously to be induced with kinetics similar to that of c-fos when quiescent fibroblasts are stimulated by growth factors. Two of these early response genes, zif/268 and nur/77, are believed to encode DNA-binding proteins that function as regulators of transcription. Sequencing of the other four early response genes has not yet given obvious clues as to their function (L.F. Lau, unpubl.).

Initially, we employed a nuclear run-on transcription assay to measure the response of the early response genes to NGF, EGF, and membrane depolarization, because this method allows the analysis of the transcription of many genes in a single experiment /Greenberg and Ziff 1984). We find that the patterns of transcriptional activation of the six additional early response genes are identical whether $\mathrm{PCl} 2$ cells are treated with EGF or with NGF (Fig. 3B). In contrast, membrane depolarization by elevated levels of $\mathrm{KCl}$ results in a different pattern of gene induction than that observed with the growth factors. As shown in Figure 3B, the glucocorticoid receptor-related gene nur/77 is induced only modestly upon the addition of NGF or EGF (2-fold) but is induced markedly by membrane depolarization (15-fold). Clone 134 also appears relatively unresponsive to growth factors in PC12 cells, but like nur/77, this gene is stimulated by membrane depolarization. The response of $z$ if $/ 268$, a gene with zinc-finger motifs, is quite different. Both NGF and EGF activated zif/268 transcription $\sim 50$-fold, whereas the effect of elevated $\mathrm{KCl}$ on zif/268 was more modest (10-fold) (Fig. 3B). The run-on transcription results were confirmed and extended by reprobing the Northern blots of Figure 1 to measure the level of induction of $z$ if/268 and nur/77 mRNA (Fig. 5). The $3.1-\mathrm{kb} z i f / 268 \mathrm{mRNA}$ is induced dramatically (>100-fold) by NGF and EGF but only to a limited extent by membrane depolarization (20-fold). The rat homolog of zif/268, termed NGFI-A, has been characterized previously in PC12 cells stimulated by NGF (Milbrandt 1987). The experiments described here indicate that

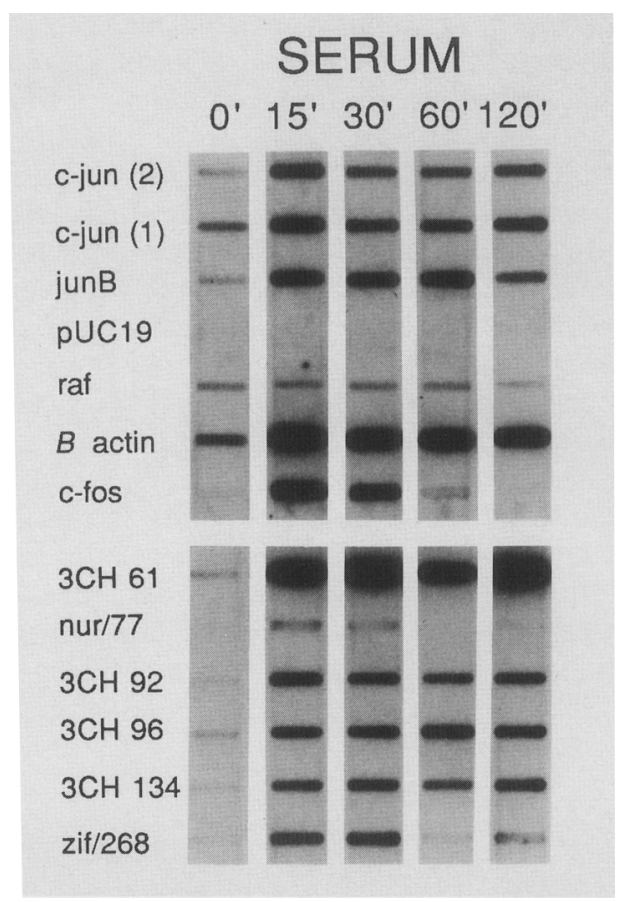

Figure 4. Transcriptional induction of early response genes in rat fibroblasts stimulated by serum. Nuclei were isolated from serum-deprived $208 \mathrm{~F}$ rat fibroblasts at different times after addition of $20 \%$ calf serum. Run-on transcripts were then assayed as described in the legend to Fig. 3.

zif/268 (NGFI-A) induction is not specific to NGF activation of $\mathrm{PC} 12$ cell differentiation but also occurs when these cells are stimulated by EGF, an agent that does not induce the differentiation of PC12 cells.

In contrast to c-jun and zif/268, the $2.6-\mathrm{kb}$ nur $/ 77$ mRNA is stimulated much more by membrane depolarization (350-fold) than by NGF and EGF (15-fold). The induction of the nur/77 mRNA by NGF in PC12 cells has been reported previously (Milbrandt 1988). A novel finding in the present study is that the nur/ $77 \mathrm{mRNA}$ is considerably more responsive to membrane depolarization than it is to growth factors. In these experiments, the differential regulation of early response gene mRNA levels is not a reflection of variability in cell stimulation by a given agent because the results in Figures 1 and 5 were obtained by successive reprobings of the same Northern blots.

The differential response of genes such as c-jun, zif/268, and nur/77 to membrane depolarization and growth factors indicates that their signal transduction pathways are distinct and do not converge. Furthermore, the different physiological responses of PC12 cells to NGF and EGF cannot be accounted for by differences in the expression of the known early response genes, because the patterns of early response gene transcription 


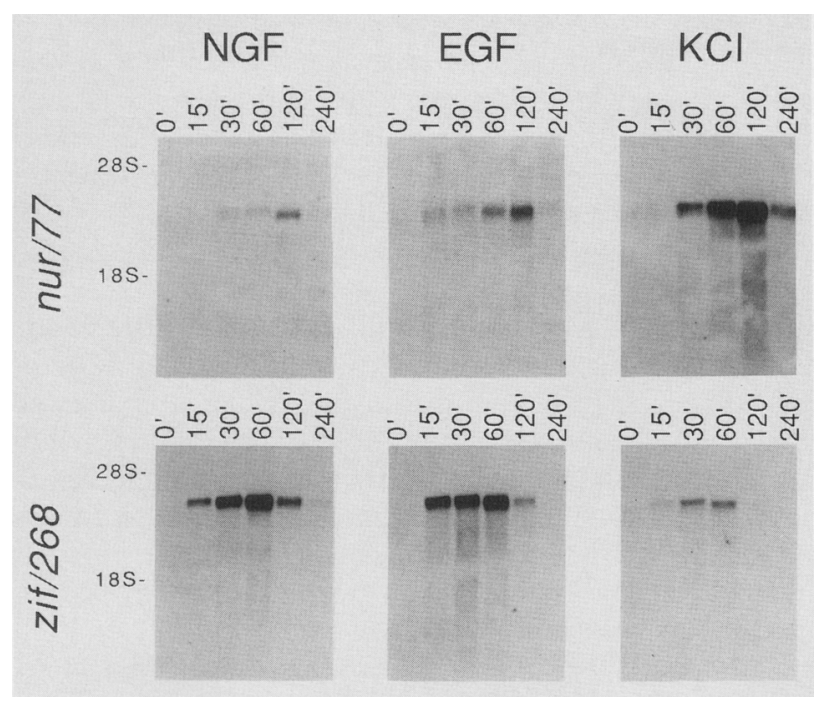

Figure 5. Induction of nur/77 and zif/268 mRNA in PC12 cells, following growth factor addition or membrane depolarization. Northern blots in Fig. 1 were stripped and rehybridized with oligoprimed ${ }^{32}$ P-labeled probes specific for nur/77 and zif/268. Positions of $28 \mathrm{~S}$ and $18 \mathrm{~S}$ ribosomal mRNAs are indicated.

were indistinguishable when NGF treatment was compared with EGF in all cases examined.

Comparison of the transcription of early response genes in fibroblasts and $\mathrm{PCl} 2$ cells reveals that the activation of clone 61 is cell type specific. Clone 61 transcription is highly responsive to serum stimulation in rat fibroblasts (Fig. 4), but is not detectable in PC12 cells stimulated by NGF, EGF, or membrane depolarization (Fig. 3B). Similar results were obtained for Krox-20 (data not shown), an early response gene with zinc-finger motifs. Clone 61 and Krox-20 were also not expressed in PC12 cells that were starved and then stimulated with calf serum (data not shown). Therefore, the inability of these genes to be activated in PC12 cells is likely to reflect a true cell type difference rather than a difference between growth factors and serum.

\section{Discussion}

$c$-fos and c-jun activation can be dissociated

In this paper, we describe experiments demonstrating that the c-jun proto-oncogene and jun-B are induced coordinately with c-fos when PC12 cells are stimulated with purified growth factors. Our results show that, as for $\mathrm{c}-f o s$, activation of $\mathrm{c}-j$ iun and jun-B occurs in a variety of cell types in response to extracellular signals. Growth factors not only induce c-jun when quiescent fibroblasts are stimulated to re-enter the cell cycle but also when an asynchronously growing population of $\mathrm{PCl} 2$ cells is stimulated by EGF to divide, or by NGF to differentiate along a neuronal pathway. Nevertheless, c-jun, jun-B, and c-fos activation can be dissociated under some circumstances. We find that transcription of $c-j u n$ is not stimulated in $\mathrm{PCl} 2$ cells following $\mathrm{KCl}$-induced membrane depolarization or treatment with the specific neurotransmitter receptor agonist nicotine. cAMP analogs also stimulate $\mathrm{c}$-fos and $j u n-\mathrm{B}$ transcription but not c-jun transcription (D.P. Bartel and M.E. Greenberg, unpubl.). Although c-jun is not induced by these agents, it is possible that the c-jun gene product still functions in stimulated cells because a basal level of $c-i u n$ mRNA is detectable. We have yet to determine the levels of the c-jun protein under various stimulation conditions, but we suspect that stimulus-specific quantitative differences in c-jun mRNA levels will be paralleled by biologically relevant differences in the expression of the c-jun protein. In addition, it seems likely that the interaction of c-jun and c-fos proteins will also be influenced by changes in the relative availability of products of the other members of the jun and fos families.

\section{NGF and EGF activate indistinguishable patterns of gene expression}

The distinct effects of NGF and EGF on PC12 cell physiology cannot be accounted for by differential induction of any of the 10 early response genes examined. It is possible that these genes are important for both growth and differentiation but that other early response genes remain to be identified that are NGF or EGF specific. Alternatively, the same set of early response genes could be transcriptionally activated by NGF and EGF, but their protein products modified differently, in a growthfactor-specific manner. Such post-translational modifications might control the activity of the Fos/Jun complexes, or other transcription factors, so that a differentiation-specific gene program results in the presence of NGF, whereas a mitogenesis-specific program is activated upon stimulation with EGF. Indeed, examination of anti-c-fos immunoprecipitates reveals that Fos and its associated proteins are differentially modified in PC12 cells stimulated by NGF compared to cells stimulated by EGF or membrane depolarization (Kruijer et al. 1985; Curran and Morgan 1986; Morgan and Curran 1986).

Growth factors and membrane depolarization activate distinct patterns of early response gene expression in PC12 cells

The patterns of early response gene activation that occur when $\mathrm{PCl} 2$ cells are membrane depolarized or exposed to cAMP analogs are quite different from those seen upon treatment with NGF or EGF. Most striking is the finding that these agents markedly induce jun-B and c-fos mRNA levels but have minimal effect on c-jun expression. Similarly, zif/268 transcription is stimulated greatly by growth factors, but to a much lesser extent by membrane depolarization. Conversely, within the same experiment, nur/77 is stimulated greatly by membrane depolarization, but to a much lesser extent by growth 
factors. Differences in the cell's long-term response to the initial stimulus may be due, at least in part, to these stimulus-specific programs of early response gene activation. The distinct pattern of gene activation that occurs upon membrane depolarization of PC12 cells may be related to adaptive changes that take place in mature neurons in response to synaptic signals. The observation that transcription of c-fos and several other early response genes is activated in the central nervous system as a consequence of electrical excitation supports this possibility (Morgan et al. 1987; Saffen et al. 1988; Sagar et al. 1988).

In addition to differential regulation within the same cell type, we have found differences between $\mathrm{PCl} 2$ cell and $208 \mathrm{~F}$ fibroblast expression of c-jun, clone 61, and Krox 20. Similar cell-type differences have also been noted in the expression of other early response genes, TIS 10 (Kujubu et al. 1987) and fra-1 (Cohen and Curran 1988). The cell type difference we observe in c-jun transcription correlates with the lower levels of p39/AP-1 detected in PC12 cells relative to fibroblasts, as analyzed by two-dimensional protein electrophoresis (Franza et al. 1987). This lower expression of c-jun in PC12 cells also correlates with lower quantities of p39/AP-1 coimmunoprecipitated with c-fos antibodies (Franza et al. 1987).

\section{Multiple signal transduction pathways regulate early response gene expression}

The finding that early response genes can be regulated differentially by growth factors and membrane depolarization within the same cell type implies that the biochemical pathways through which these agents act must be at least partly distinct. NGF and EGF activation of c-fos in PC12 cells is mediated through a serum response element (SRE; Treisman 1985) located $\sim 300$ bp upstream of the mRNA initiation site (Sheng et al. 1988). The dyad symmetry element within the SRE binds a protein, serum response factor (SRF), that is present in nuclear extracts of PC12 cells (Sheng et al. 1988) and is believed to regulate growth factor induction of c-fos transcription (Gilman et al. 1986; Prywes and Roeder 1986; Treisman 1986; Greenberg et al. 1987). Similar dyad symmetry elements present upstream of two other early response genes, $\beta$-actin (Greenberg et al. 1987; Mohun et al. 1987) and zif/286 (Christy et al. 1988; M. Thompson and M.E. Greenberg, unpubl.), recently have been shown to bind SRF and may be important for the growth factor response. It is unclear at present whether all growth-factor-inducible genes use this SRF-mediated pathway or whether other promoter regulatory elements are involved (Angel et al. 1988a).

Recent studies have identified a second distinct pathway for c-fos induction that is independent of the SRE (Buscher et al. 1988; Gilman 1988; Sassone-Corsi et al. 1988c; Sheng et al. 1988). This alternative pathway is activated by membrane depolarization or cAMP analogs and uses an element located $\sim 60$ bp upstream of the c-fos mRNA initiation site, which bears sequence ho- mology to the cAMP response element (CRE) (Sheng et al. 1988). The family of early response genes that are activated by elevated $\mathrm{KCl}$, nicotine, and cAMP also may use a regulatory element similar to the -60 element of c-fos. Recent evidence that a CRE-like sequence is present upstream of zif/268 (Christy et al. 1988), one of the early response genes that is responsive to membrane depolarization, supports this idea.

The observation that growth factors and membrane depolarization have dissociable effects on a number of early response genes confirms the conclusion derived from studies of $\mathrm{c}$-fos promoter mutants that independent pathways exist for the transduction of these signals to the nucleus. The existence of nonconvergent pathways for early response gene activation provides the proteins encoded by these genes with greater versatility as nuclear mediators of extracellular signals. Distinct combinations of early response genes can be activated in response to different stimuli, providing an explanation as to how a relatively small number of regulatory genes may control a diverse set of responses. Furthermore, if the early response gene products are involved in heteromeric transcription regulatory complexes, as is the case with fos and jun, then an even greater level of combinatorial complexity could be generated. We speculate that such combinatorial control mechanisms may account for both the diversity and specificity of cellular responses to environmental change.

\section{Materials and methods}

\section{Plasmid DNA}

Cloned immediate early gene cDNAs used for hybridization probes in Northern blot analysis and nuclear run-on transcription assays were obtained as follows: jun-B (Ryder et al. 1988, a gift from D. Nathans), c-fos (Halazonetis et al. 1988), zif/268, nur $/ 77,3 \mathrm{CH} 61,3 \mathrm{CH} 92,3 \mathrm{CH} 96$, and $3 \mathrm{CH} 134$ were derived from a cDNA library from serum-induced mouse fibroblasts (Lau and Nathans 1985, 1987). Probes c-jun(1) and c-jun(2) were derived from partial human c-jun cDNA clones, which were kindly provided by M. Karin (Angel et al. 1988b). Krox-20 was a gift from P. Charnay (Lemaire et al. 1988). B-Actin and raf clones have been described previously (Greenberg and Ziff 1984).

\section{Cell culture and stimulation}

$\mathrm{PC} 12$ cells were plated on tissue culture dishes coated with rat tail collagen and grown as described previously (Sheng et al. 1988). Rat 208F fibroblasts were grown in Dulbecco's modified Eagle's medium (DMEM) containing $10 \%$ calf serum in $10 \%$ $\mathrm{CO}_{2}$.

$\mathrm{PC} 12$ cells were stimulated as described in the figure legends with EGF (3 ng/ml), NGF $(50 \mathrm{ng} / \mathrm{ml})$, or nicotine $(0.10 \mathrm{~mm})$ (Sigma, St. Louis, Missouri). $\mathrm{KCl}$ depolarization was achieved by adding potassium chloride and calcium chloride to the culture medium to a final concentration of $60 \mathrm{mM}$ and $10 \mathrm{mM}$, respectively, except for the depolarization of NGF-differentiated PCl2 cells (Fig. 2), where calcium chloride was omitted.

Rat $208 \mathrm{~F}$ fibroblasts were made quiescent by incubation in DMEM containing $0.5 \%$ calf serum for 2 days and stimulated 
by the addition of fresh medium containing $20 \%$ fetal calf serum.

The sources of cell culture and cell stimulation reagents have been described previously (Sheng et al. 1988).

\section{Northern blot analysis}

Total cytoplasmic RNA was isolated (Greenberg and Ziff 1984; Greenberg et al. 1986) and 15- $\mu$ g samples fractionated by electrophoresis through $1 \mathrm{M}$ formaldehyde/ $1.2 \%$ agarose gels. The RNA was transferred to GeneScreen membranes (NEN Research Products, Boston, Massachusetts) and cross-linked to the nylon by UV irradiation. Prehybridization and hybridization conditions were as recommended by the manufacturer. After hybridization, the membranes were washed in $2 \times \mathrm{SSC} / 1 \%$ SDS for $30 \mathrm{~min}$ at $65^{\circ} \mathrm{C}$ and, subsequently, in $0.1 \times \mathrm{SSC}$ for 30 min at room temperature. When more than one blot was probed for the same RNA species (Figs. 1 and 5), hybridization and washing conditions were identical between blots.

Gene-specific DNA probes were prepared by the random oligonucleotide priming method, using gel-purified cDNA fragments and an Oligo-Labeling Kit (Pharmacia LKB Biotechnology, Piscataway, New Jerseyl.

After autoradiography, membranes were stripped of radioactivity by boiling in $10 \mathrm{~mm}$ Tris (pH 7.5), $1 \mathrm{~mm}$ EDTA, and $1 \%$ SDS before reprobing.

\section{Nuclear run-on transcription assay}

Experimental procedures for the in vitro nuclear run-on transcription assay have been described in detail previously (Greenberg and Ziff 1984).

\section{Acknowledgments}

This work was supported by grant RO1 CA 43855 from the National Institutes of Health. M.E.G. is the recipient of an American Cancer Society Junior Faculty Research Award (JFRA-179) and is a Searle Scholar supported by the Chicago Community Trust. D.P.B. is supported by predoctoral training grant T32 AIO 7245 from the National Institute of Allergy and Infectious Disease. M.S. is supported by a Lucille P. Markey predoctoral fellowship. L.F.L. is the recipient of an American Cancer Society Junior Faculty Research Award (JFRA-220) and is a Pew Scholar in the Biomedical Sciences.

\section{References}

Almendral, J.M., D. Sommer, H. MacDonald-Bravo, J. Burckhardt, J. Perera, and R. Bravo. 1988. Complexity of the early genetic response to growth factors in mouse fibroblasts. Mol. Cell. Biol. 8: 2140-2148.

Amy, C.M. and E.L. Bennett. 1983. Increased sodium ion conductance through nicotinic acetylcholine receptor channels in PC12 cells exposed to nerve growth factor. J. Neurosci. 3: $1547-1553$.

Angel, P., K. Hattori, T. Smeal, and M. Karin. 1988a. The jun proto-oncogene is positively autoregulated by its product, jun/AP-1. Cell 55: 875-885.

Angel, P., E.A. Allegretto, S.T. Okino, K. Hattori, W.J. Boyle, T. Hunter, and M. Karin. 1988b. Oncogene iun encodes a sequence-specific trans-activator similar to AP-1. Nature 332: $166-171$.
Angel, P., M. Imagawa, R. Chiu, B. Stein, R.J. Imbra, H.J. Rahmsdorf, C. Jonat, P. Herrlich, and M. Karin. 1987. Phorbol ester-inducible genes contain a common cis element recognized by a TPA-modulated trans-acting factor. Cell 49: 729-739.

Bohmann, D., T.J. Bos, A. Admon, T. Nishimura, P.K. Vogt, and R. Tiian. 1987. Human proto-oncogene c-jun encodes a DNA binding protein with structural and functional properties of transcription factor AP-1. Science 238: 1386-1392.

Boonstra, J., W.H. Moolenaar, P.H. Harrison, P. Moed, P.T. van der Saag, and S.W. de Laat. 1983. Ionic responses and growth stimulation induced by nerve growth factor and epidermal growth factor in rat pheochromocytoma (PC12) cells. J. Cell Biol. 97: 92-98.

Buscher, M., H.J. Rahmsdorf, M. Litfin, M. Karin, and P. Herrlich. 1988. Activation of the c-fos gene by UV and phorbol ester: Different signal transduction pathways converge to the same enhancer element. Oncogene 3: 301-311.

Chavrier, P., M. Zerial, P. Lemaire, J. Almendral, R. Bravo, and P. Charnay. 1988. A gene encoding a protein with zinc fingers is activated during G0/G1 transition in cultured cells. EMBO J. 7: 29-35.

Chiu, R., W.J. Boyle, J. Meek, T. Smeal, T. Hunter, and M. Karin. 1988. The c-fos protein interacts with c-jun/AP-1 to stimulate transcription of AP-1 responsive genes. Cell 54: $541-552$.

Christy, B.A., L.F. Lau, and D. Nathans. 1988. A gene activated in mouse $3 \mathrm{~T} 3$ cells by serum growth factors encodes a protein with 'zinc finger' sequences. Proc. Natl. Acad. Sci. 85: 7857-7861.

Cochran, B.H., A.C. Reffel, and C.D. Stiles. 1983. Molecular cloning of gene sequences regulated by platelet-derived growth factor. Cell 33: 939-947.

Cochran, B.H., J. Zullo, I.M. Verma, and C.D. Stiles. 1984. Expression of the c-fos gene and of a fos-related gene is stimulated by platelet-derived growth factor. Science 226: 1080 1082.

Cohen, D.R. and T. Curran. 1988. fra-1: A serum-inducible, cellular immediate-early gene that encodes a Fos-related antigen. Mol. Cell. Biol. 8: 2063-2069.

Curran, T. and B.R. Franza, Jr. 1988. Fos and Jun: The AP-1 connection. Cell 55: 395-397.

Curran, T. and J.I. Morgan. 1985. Superinduction of the fos gene by nerve growth factor in the presence of peripherally active Benzodiazepines. Science 229: 1265-1268.

- 1986. Barium modulates c-fos expression and posttranslational modification. Proc. Natl. Acad. Sci. 83: 85218524.

Dichter, M.A., A.S. Tischler, and L.A. Greene. 1977. Nerve growth factor-induced change in electrical excitability and acetylcholine sensitivity of a rat pheochromocytoma cell line. Nature 268: 501-504.

Franza, B.R., L.C. Sambucetti, D.R. Cohen, and T. Curran. 1987. Analysis of Fos protein complexes and Fos-related antigens by high-resolution two-dimensional gel electrophoresis. Oncogene 1: 213-221.

Gilman, M.Z. 1988. The c-fos serum response element responds to protein kinase c-dependent and -independent signals, but not to cyclic AMP. Genes Dev. 2: 394-402.

Gilman, M.Z., R.N. Wilson, and R.A. Weinberg. 1986. Multiple protein binding sites in the $5^{\prime}$-flanking region regulate c-fos expression. Mol. Cell. Biol. 6: 4305-4315.

Greenberg, M.E. and E.B. Ziff. 1984. Stimulation of 3T3 cells induces transcription of the c-fos proto-oncogene. Nature 311: $433-438$

Greenberg, M.E., L.A. Greene, and E.B. Ziff. 1985. Nerve 
growth factor and epidermal growth factor induce transient changes in proto-oncogene transcription in $\mathrm{PCl} 2$ cells. $J$. Biol. Chem. 260: 14101-14110.

Greenberg, M.E., Z. Siegfried, and E.B. Ziff. 1987. Mutation of the c-fos dyad symmetry element inhibits serum inducibility in vivo and nuclear regulatory factor binding in vitro. Mol. Cell. Biol. 7: 1217-1225.

Greenberg, M.E., E.B. Ziff, and L.A. Greene. 1986. Stimulation of neuronal acetylcholine receptors induces rapid gene transcription. Science 234: 80-83.

Greene, L.A. and A.S. Tischler. 1976. Establishment of a noradrenergic clonal line of rat adrenal pheochromocytoma cells which respond to nerve growth factor. Proc. Natl. Acad. Sci. 73: $2424-2428$.

- 1982. PC12 Pheochromocytoma cultures in neurobiological research. Adv. Cell. Neurobiol. 3: 373-414.

Halazonetis, T.D., K. Georgopoulos, M.E. Greenberg, and P. Leder. 1988. c-jun dimerizes with itself and with c-fos, forming complexes of different DNA binding affinities. Cell 55: $917-924$.

Hazel, T.G., D. Nathans, and L.F. Lau. 1988. A gene inducible by serum growth factors encodes a member of the steroid and thyroid hormone receptor superfamily. Proc. Natl. Acad. Sci. 85: 8444-8448.

Joseph, L.J., M.M. Le Beau, G.A. Jamieson Jr., S. Acharya, T.B. Shows, J.D. Rowley, and V.P. Sukhatme. 1988. Molecular cloning, sequencing, and mapping of EGR2, a human early growth response gene encoding a protein with 'zinc-binding finger' structure. Proc. Natl. Acad. Sci. 85: 7164-7168.

Jumblatt, J.E. and A.S. Tischler. 1982. Regulation of muscarinic ligand binding sites by nerve growth factor in $\mathrm{PC} 12$ phaeochromocytoma cells. Nature 297: 152-154.

Kouzarides, T. and E. Ziff. 1988. The role of the leucine zipper in the fos-jun interaction. Nature 336: 646-651.

Kruijer, W., D. Schubert, and I.M. Verma. 1985. Induction of the proto-oncogene fos by nerve growth factor. Proc. Natl. Acad. Sci. 82: 7330-7334.

Kruijer, W., J.A. Cooper, T. Hunter, and I.M. Verma. 1984. Platelet-derived growth factor induces rapid but transient expression of the c-fos gene and protein. Nature 312: 711716.

Kujubu, D.A., R.W. Lim, B.C. Varnum, and H.R. Herschman. 1987. Induction of transiently expressed genes in PC-12 pheochromocytoma cells. Oncogene 1: 257-262.

Lamph, W.W., P. Wamsley, P. Sassone-Corsi, and I.M. Verma. 1988. Induction of proto-oncogene /UN/AP-1 by serum and TPA. Nature 334: 629-631.

Lau, L.F. and D. Nathans. 1985. Identification of a set of genes expressed during the G0/G1 transition of cultured mouse cells. EMBO I. 4: 3145-3151.

-1987. Expression of a set of growth- related immediate early genes in $\mathrm{BALB} / \mathrm{c} 3 \mathrm{~T} 3$ cells: Coordinate regulation with c-fos or c-myc. Proc. Natl. Acad. Sci. 84: 1182-1186.

Lee, W., P. Mitchell, and R. Tjian. 1987. Purified transcription factor AP-1 interacts with TPA-inducible enhancer elements. Cell 49: 741-752.

Lemaire, P., O. Revelant, R. Bravo, and P. Charnay. 1988. Two mouse genes encoding potential transcription factors with identical DNA-binding domains are activated by growth factors in cultured cells. Proc. Natl. Acad. Sci. 85: 46914695.

Lim, R. W., B.C. Varnum, and H.R. Herschman. 1987. Cloning of tetradecanoyl phorbol ester-induced primary response sequences and their expression in density-arrested Swiss 3T3 cells and a TPA non-proliferative variant. Oncogene 1: 263270.
Maki, Y., T.J. Bos, C. Davis, M. Starbuck, and P.K. Vogt. 1987. Avian sarcoma virus 17 carries the jun oncogene. Proc. Natl. Acad. Sci. 84: 2848-2852.

Milbrandt, J. 1987. A nerve growth factor-induced gene encodes a possible transcriptional regulatory factor. Science 238: 797-799.

-1988. Nerve growth factor induces a gene homologous to the glucocorticoid receptor gene. Neuron 1: 183-188.

Mohun, T., N. Garrett, and R. Treisman. 1987. Xenopus cytoskeletal actin and human c-fos promoters share a conserved protein binding site. EMBO I. 6: 667-673.

Morgan, J.I. and T. Curran. 1986. Role of ion flux in the control of c-fos expression. Nature 322: 552-555.

Morgan, J., D. Cohen, J. Hempstead, and T. Curran. 1987. Mapping patterns of c-fos expression in the central nervous system after seizure. Science 237: 192-197.

Muller, T., T. Bravo, J. Burckhardt, and T. Curran. 1984. Induction of c-fos gene and protein by growth factors precedes activation of c-myc. Nature 312: 716-720.

Nakabeppu, Y., K. Ryder, and D. Nathans. 1988. DNA binding activities of three murine jun proteins: stimulation by fos. Cell 55: 907-915.

Prywes, R. and R.G. Roeder. 1986. Inducible binding of a factor to the c-fos enhancer. Cell 47: 777-784.

Quantin, B., and R. Breathnach. 1988. Epidermal growth factor stimulates transcription of the c-jun proto-oncogene in rat fibroblasts. Nature 334: 538-539.

Rauscher, F.J., P.J. Voulalas, B.R. Franza, and T. Curran. 1988a. Fos and Jun bind cooperatively to the AP-1 site: reconstruction in vitro. Genes Dev. 2: 1687-1699.

Rauscher, F.J., D.R. Cohen, T. Curran, T.J. Bos, P.K. Vogt, D. Bohmann, R. Tjian, and B.R. Franza, Jr. 1988b. Fos-associated protein $\mathrm{p} 39$ is the product of the jun proto-oncogene. Science 240: 1010-1016.

Ryder, K. and D. Nathans. 1988. Induction of proto-oncogene c-jun by serum growth factors. Proc. Natl. Acad. Sci. 85: 8464-8467.

Ryder, K., L.F. Lau, and D. Nathans. 1988 A gene activated by growth factors is related to the oncogene v-jun. Proc. Natl. Acad. Sci. 85: 1487-1491.

Ryseck, R.-P., S.I. Hirai, M. Yaniv, and R. Bravo. 1988. Transcriptional activation of c-jun during the G0/G1 transition in mouse fibroblasts. Nature 334: 535-537.

Saffen, D.W., A.J. Cole, P.F. Worley, B.A. Christy, K. Ryder, and J.M. Baraban. 1988. Convulsant-induced increase in transcription factor messenger RNAs in rat brain. Proc. Natl. Acad. Sci. 85: 7795-7799.

Sagar, S.M., F.R. Sharp, and T. Curran. 1988. Expression of c-fos protein in brain: Metabolic mapping at the cellular level. Science 240: 1328-1331.

Sassone-Corsi, P., W.W. Lamph, M. Kamps, and I.M. Verma. 1988a. fos-associated cellular p39 is related to nuclear transcription factor AP-1. Cell 54: 553-560.

Sassone-Corsi, P., L.J. Ransone, W.W. Lamph, and I.M. Verma. $1988 \mathrm{~b}$. Direct interaction between fos and jun nuclear oncoproteins: Role of the 'leucine zipper' domain. Nature 336: 692-695.

Sassone-Corsi, P., J. Visvader, L. Ferland, P.L. Mellon, and I.M. Verma. 1988c. Induction of proto-oncogene fos transcription through the adenylate cyclase pathway: Characterization of a cAMP-responsive element. Genes Dev. 2: 1529-1538.

Sheng. M., S.T. Dougan, G. McFadden, and M.E. Greenberg. 1988. Calcium and growth factor pathways of c-fos transcriptional activation require distinct upstream regulatory sequences. Mol. Cell. Biol. 8: 2787-2796.

Sukhatme, V.P., S. Kartha, F.G. Toback, R. Taub, R.G. Hoover, 
and C.H. Tsai-Morris. 1987. A novel early growth response gene rapidly induced by fibroblast, epithelial cell and lymphocyte mitogens. Oncogene Res. 1: 343-355.

Sukhatme, V.P., X. Cao, L.C. Chang, C.-H. Tsai-Morris, D. Stamenkovich, P.C.P. Ferreira, D.R. Cohen, S.A. Edwards, T.B. Shows, T.Curran, M.M. Le Beau, and E.D. Adamson. 1988. A zinc finger-encoding gene coregulated with c-fos during growth and differentiation, and after cellular depolarization. Cell 53: 37- 43.

Treisman, R. 1985. Transient accumulation of c-fos RNA following serum stimulation requires a conserved 5 ' element and c-fos 3' sequences. Cell 42: 889-902.

. 1986. Identification of a protein-binding site that mediates transcriptional response of the c-fos gene to serum factors. Cell 46: 567-574. 


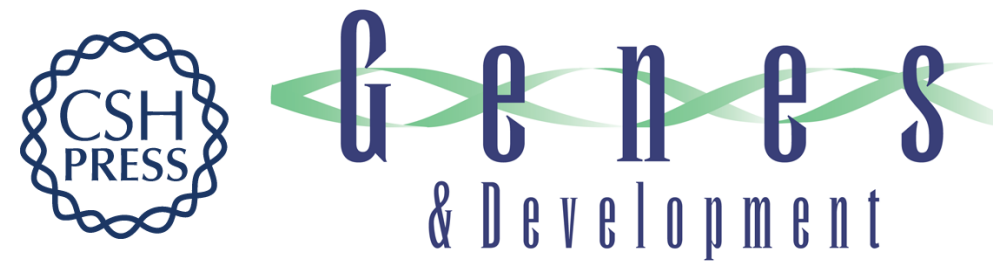

\section{Growth factors and membrane depolarization activate distinct programs of early response gene expression: dissociation of fos and jun induction.}

D P Bartel, M Sheng, L F Lau, et al.

Genes Dev. 1989, 3:

Access the most recent version at doi:10.1101/gad.3.3.304

References This article cites 66 articles, 31 of which can be accessed free at:

http://genesdev.cshlp.org/content/3/3/304.full.html\#ref-list-1

License

Email Alerting Receive free email alerts when new articles cite this article - sign up in the box at the top Service right corner of the article or click here.

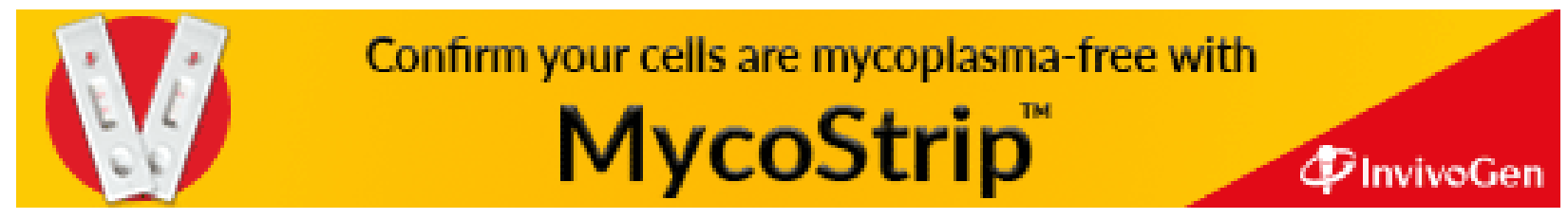

